\title{
The Role of Oncology Pharmacists in optimizing patient care in Chronic Immune Thrombocytopenia
}

\author{
Bedanta Bhattacharjee 1 , Bhargab Deka 1 , Nasima Ahmed 1 , Bonti Sonowal 1 , Arzoo \\ Newar 1, Ashique Ahmed 1, Abu Md Ashif Ikbal 2, Amlanjyoti Rajkhowa 2, Alakesh \\ Bharali 3 , Gargi Das 4 , Ritu Bharti 5 , Ripon Sinha 5 \\ 1 Department of Pharmaceutical Sciences, Faculty of Science and Engineering, Dibrugarh \\ University, Dibrugarh-786004, Assam, India \\ 2 Department of Pharmacy, Tripura University (A Central University), Suryamaninagar- \\ 799022, Tripura (W), India \\ 3 Department of Pharmacy, Girijananda Chowdhury Institute of Pharmaceutical Sciences- \\ 781017, Guwahati, Assam, India \\ 4 Department of Pharmacy, Himalayan Pharmacy Institute, Majhitar, East Sikkim-737136, \\ Sikkim, India \\ 5 Shri Guru Ram Rai University, Patel Nagar, Dehradun-248001, Uttrakhand, India
}

\begin{abstract}
Immune thrombocytopenia or ITP is an autoimmune disorder in which the body creates autoantibodies against its thrombocytes or platelets that are destroyed, resulting in purpura or minor bleeding spots under the surface. It is most often found in cancer patients and is of growing concern. While the main causes of thrombocytopenia in cancer patients are chemotherapy and radiation, other aetiologies should also be considered in patients suffering from this debilitating disease. Thrombocytopenia causes a variety of complications in the treatment of cancer patients and therefore pharmacists need to be familiar with epidemiology, pathophysiology, risk factors, diagnostic methods, and emerging therapeutic options for chronic immune thrombocytopenia to help oncologists identify and implement realistic treatment measures for chronic immune thrombocytopenia patients undergoing cancer treatment. The objective of this review is to provide a brief overview of chronic immune thrombocytopenia and various strategies for the clinical management of the disease.
\end{abstract}

Keywords: Immune thrombocytopenia, Autoimmune, Chemotherapy, Clinical management.

\section{Introduction}

Immune thrombocytopenia is an autoimmune bleeding disorder with a noccurrence rate in the United States of about 60,000 adults [1].Immune thrombocytopenia is facilitated by platelet antibodies that speed up the destruction of platelets and inhibit their origination. The majority of immune thrombocytopenia cases are considered primary, while others are associated with pre-existing conditions and are considered secondary immune thrombocytopenia [2]. Over the years, the distinctions have been less specified between primary and secondary immune thrombocytopenia. The initial cause of antiplatelet autoimmunity is unclear, but there is good 


\section{ISSN 2515-8260 Volume 08, Issue 03, 2021}

evidence that auto-reactive CD8 cytotoxic T-cells and autoantibodies activate platelet degradation and reduce platelet production in the bone marrow by megakaryocytes[3]. Immune thrombocytopenia occurs both in adults and children, but there may be fundamentally different underlying disease processes in childhood immune thrombocytopenia and adult immune thrombocytopenia.In adults, immune thrombocytopenia is more often a chronic condition, although most pediatric patients have acute immune thrombocytopenia[4].

\section{Pathophysiology of ChronicImmune Thrombocy topenia}

On average, about 100 billion platelets a day are formed by the human body, resulting in a concentration of 150,000 to 400,000 platelets per microliter of blood[3].Platelets circulate for roughly 7 to 10 days, steadily experiencing age-related morphological changes, activation, and surface receptor density[3]. Stem cells differentiate into megakaryocyte cells. Finally, mature megakaryocytesthen produce platelets as shown in Figure 1[5]. At various stages, some anti-cancer drugs affect the production pathway of megakaryocyte and platelet[5].

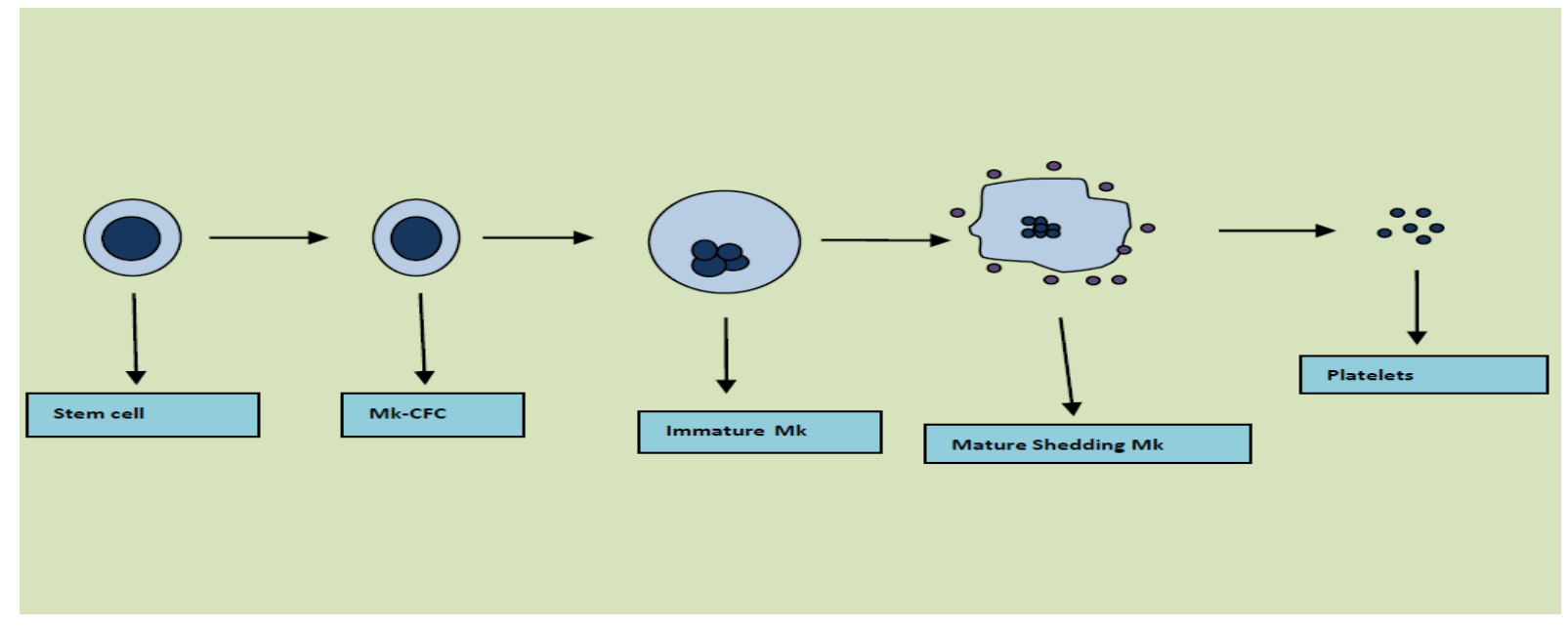

Figure 1: Production of platelets from bone marrow stem cells.

The main regulator of platelet synthesis is the hematopoietic growth factor thrombopoietin [3].It is synthesized primarily in the liver and help megakaryocyte to produce platelets in the bone marrow. Since hepatocytes release newly made thrombopoietin into the bloodstream, it is also incorporated into circulating platelets. This is an inhibitory feedback loop in which platelet counts correlate inversely with the volume of thrombopoietin accessing the bone marrow to promote the development of new platelets [3].

In immune thrombocytopenia, this normal platelet life cycle is disturbed by impaired megakaryocytopoiesis, T-cell-mediated destruction of platelets, and antiplatelet autoantibodies as depicted in Figure 2[4,5].Multiple aspects of the platelet life cycle, including their formation and clearance resulting in thrombocytopenia, can interfere with CD8+ cytotoxic T-cells and autoantibodies. Platelet-specific immunoglobulin G antibodies have been found in $60 \%$ to $70 \%$ of patients with immune thrombocytopenia. In certain cases, an elevated risk of thrombosis has been linked with the presence of antiplatelet antibodies [4]. 


\section{ISSN 2515-8260 Volume 08, Issue 03, 2021}

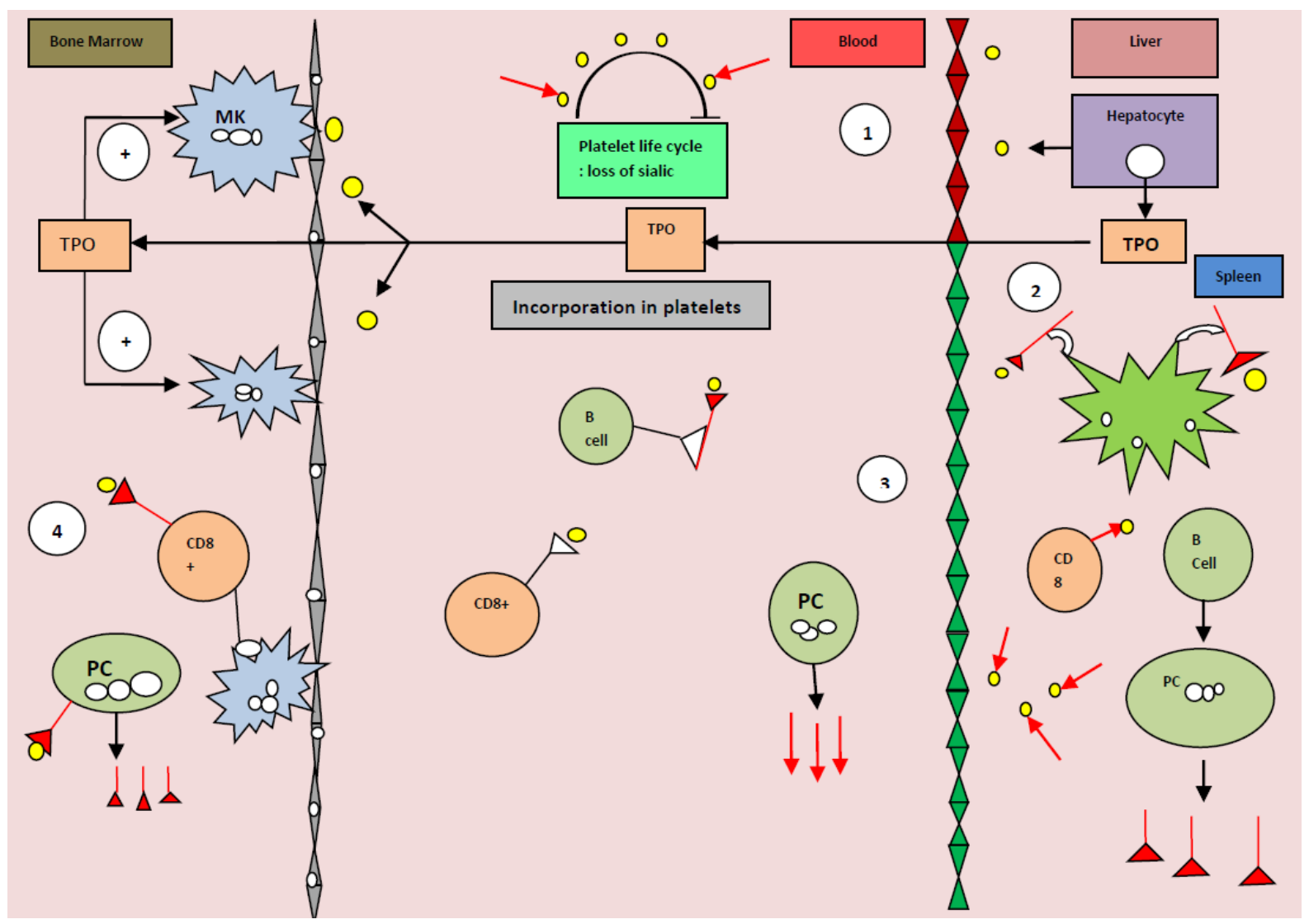

Figure 2: Disturbance of the platelet life cycle in immune thrombocytopenia.

\section{Diagnosis of Chronic Immune Thrombocytopenia}

At present, there is no conclusive clinical procedure for the diagnosis of immune thrombocytopenia. Immune thrombocytopenia diagnosis is normally made by a peripheral blood smear examination and appraisal of the patient's history [4]. Testing of platelet function seems successful in predicting the risk of bleeding [3]. However, there are no biomarkers exists that can predict treatment response against immune thrombocytopenia [3]. Patients who experience thrombocytopenia with a platelet count of less than $100,000 / \mathrm{mm}^{3}$ with no other apparent underlying cause are diagnosed with primary immune thrombocytopenia. The recommendations of the American Society of Haematology and the International Immune Thrombocytopenia Working Group do not prescribe systematic monitoring of antiplatelet antibodies for the diagnosis immune thrombocytopenia[4]. Secondary immune thrombocytopenia is characterized as immune thrombocytopenia caused by another disease or by other treatments. These may include infectious causes, autoimmune and lymphoproliferative disorders, transfusion, or theuse of certain medications [3].Medications linked to secondary causes of immune thrombocytopenia include quinidine, acetaminophen, abciximab, carbamazepine, rifampicin, and vancomycin[6]. It is important to note that chemotherapy-induced thrombocytopenia is not considered the same as drug-induced immune thrombocytopenia. Thus, it is important to understanding a patient's history to rule out other causesof chronic immune thrombocytopeniasuch as infections, autoimmune disorders, bone marrow diseases, liver disease, recent transfusion, and vaccinations or other drug exposures is necessary. Screening for Helicobacter pylori may also be necessary as this 


\section{ISSN 2515-8260 Volume 08, Issue 03, 2021}

infection has been linked to immune thrombocytopenia. Infections may sometimes lead to such strong antiplatelet immune response that it may continue and develop into chronic immune thrombocytopenia[4].

Apart from the bleeding manifestations, a physical examination is typically normal[7]. A complete blood count is required having platelet count less than $100,000 / \mathrm{mm}^{3}$ is the threshold for diagnosis. Bone marrow biopsy may be helpful in patients under 60 years of age or when bone marrow disease is suspected[4]. Similarly, chronic immune thrombocytopenia is more frequent in older patients, and the incidence rises with age [3]. In immune thrombocytopenia, the average incidence of bleeding is low; it is higher in persons with platelet counts lower than $10,000 / \mathrm{mm}^{3}$. The clinical presentation includes symptoms such as blood blisters on the inside of cheeks, bruising, petechiae, gum bleeding, frequent nose bleeds, and menstrual bleeding. Frequent bleeding episodes may result in anemia and rare cases of intracranial hemorrhage. Fatigue, anxiety, and depression are common for patients with immune thrombocytopenia $[4,8]$.

Based on the available literature, Swinkelset al.proposed a simplistic model of immune thrombocytopenia pathogenesis in which both loss of tolerance and exposure of platelet antigens are required to induce immune thrombocytopenia as shown in Figure 3[3].

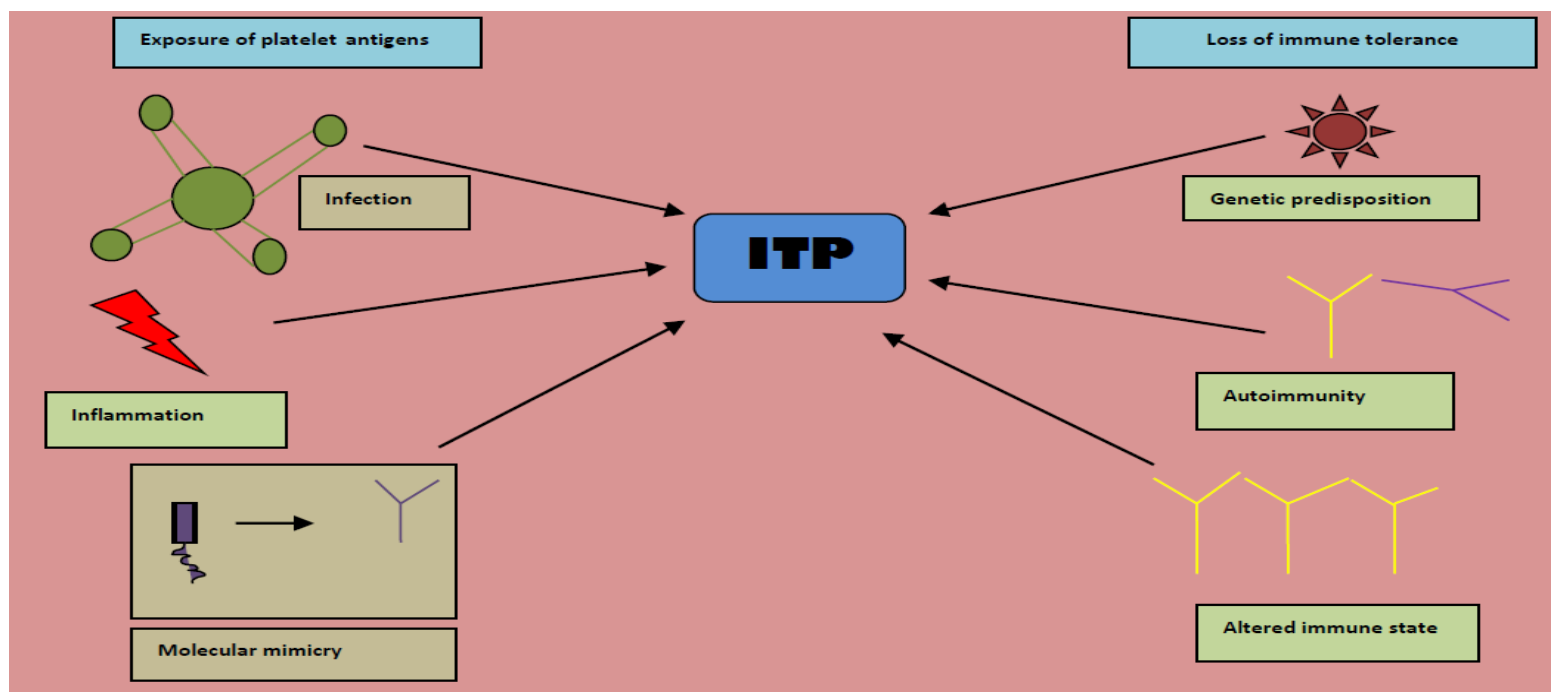

Figure 3: Model for immune thrombocytopenia pathogenesis.

\section{Impact of Chronic Immune Thrombocytopenia}

The effect of immune thrombocytopenia, especially chronic immune thrombocytopenia, on the quality of life of patients, is important in terms of health[7].Extreme fatigue, recorded in $39 \%$ to $59 \%$ of adult patients with immune thrombocytopenia, is the most complicated symptom ofimmune thrombocytopenia to treat, although it is recognized by health care providers [6,7]. Immune thrombocytopenia contributes to diminished quality of life in the areas of emotional, reproductive, functional, and wellbeing, and affects everyday life, impacting mental health in turn [7]. The key aim of the treatment of chronic immune thrombocytopenia is to produce a consistent rise in the number of platelets that are considered hemostatic for the particular patient, thus minimizing adverse effects and allowing remission to be [6,7]. A hemostatic platelet count is typically around 20,000 to $30,000 / \mathrm{mm}^{3}$. Treatment 


\section{ISSN 2515-8260 Volume 08, Issue 03, 2021}

may be reserved for patients with symptomatic immune thrombocytopenia. Treatment should be personalized to each patient, taking into consideration the platelet count, age, comorbidities, timeline for remission, dosage form, and bleeding risk[9]. In 2019, the American Society of Hematology and the International Consensus Report both published guidelines for the treatment of immune thrombocytopenia[7,8]. The American Society of hematology guidelines incorporate data published up to May 2017. The International Consensus Report includes published up to July 2018. Of note, the American Society of Hematology guidelines do not include the most recently approved spleen tyrosine kinase inhibitor fostamatinib, nor does it include thethrombopoietin receptor agonist, avatrombopag[7]. In contrast, the International Consensus Report guidelines include information on the efficacy and safety of both avatrombopag and fostamatinib and recommendations for incorporating these into the treatment landscape. Treatment for chronic immune thrombocytopenia may influence patients undergoing cancer treatment[5]. The most common impact is a reduction of the dose intensity of chemotherapy or radiation; alternatively, practitioners can determine a more effective regimen to avoid thrombocytopenic toxicity, but treatment may need to be interrupted. Underlying treatment goals of the individual patient with cancer will determine the approach to therapy, along with the different levels of risk assessment for patients being treated for cure versus those receiving palliative therapy[5].

\section{Newly Diagnosed Immune Thrombocytopenia}

Newly diagnosed immune thrombocytopenia is characterized as a span of fewer than 3 months of immune thrombocytopenia [8]. Corticosteroids are the standard for treated newly diagnosed immune thrombocytopenia unless the patient is a candidate for observation (platelet count higher than $30,000 / \mathrm{mm}^{3}$ and asymptomatic)[8]. Corticosteroid therapy can decrease the rate of platelet destruction and rapidly change the integrity of endothelial cells to promote primary hemostasis, thus decreasing bruising and bleeding [10]. Prednisone and dexamethasone have been found to modulate the activation of B-cell and dendritic cell, contributing to reduced immune-mediated degradation of platelets [9]. The American Society of hematology advisory panel recommends either prednisone $(0.5-2.0 \mathrm{mg} / \mathrm{kg} / \mathrm{day})$ or dexamethasone (40 mg/day for 4 days) as initial corticosteroid treatment [8]. A survey of 125 patients with an initial platelet count of less than $20,000 / \mathrm{mm}^{3}$ found that a single short course of dexamethasone (40 mg per day for 4 days) resulted in a platelet count of more than $50,000 / \mathrm{mm}^{3}$ in $50 \%$ of those surveyed [11]. It is important to monitor for adverse effects of steroid therapy, such as hypertension, hyperglycemia, insomnia, mood disturbances, ulcers, glaucoma, myopathy, osteoporosis, and depression. For certain patients, the adverse effect profile can be a concern, but corticosteroids are usually considered safe and are an easy therapeutic choice to offer.Long-term use of steroids ( $>6$ weeks) is not recommended by the American Society of Haematology, given the potential impact on mood, sleep and weight gain[8]. Rituximab may be considered in combination with steroids when the goal is to achieve rapid remission; however, the American Society of Hematology guidance notes that corticosteroid monotherapy is preferred[8].

Intravenous immunoglobulin or anti- D immune globulin can be used as a first-line treatment in patients with contraindicated high-dose steroids[7]. Also, patients with maternal immune 


\section{ISSN 2515-8260 Volume 08, Issue 03, 2021}

thrombocytopenia and a Rhesus ( $\mathrm{Rh}$ )-positive blood type who have not received a splenectomy and do not have autoimmune hemolyticanemia may be treated with IV anti-D immune globulin[7]. Treatment with high-dose (0.8-2 grams $/ \mathrm{kg})$ intravenous immunoglobulin has been shown to increase plateletcounts after just 1 day of treatment. A study of 19 patients with chronic immune thrombocytopenia showed an 84\% response rate for an increase in platelet count and a $100 \%$ response rate for bleeding cessation at 24 hours with intravenous immunoglobulin, with an increase in platelet count within 1 hour in $53 \%$ of patients[12]. Unfortunately, the effect of intravenous immunoglobulin just lasts 1 to 2 weeks. Platelet transfusion may be initiated in life-threatening bleeds, but may otherwise be unsuccessful because of the intermittent effect. Additionally, anti-fibrinolytic treatment can help stop bleeding in life-threatening scenarios[6].

\section{Persistent and Chronic Immune Thrombocytope nia}

Persistent immune thrombocytopenia is identified by 3 to 12 months in duration, and chronic immune thrombocytopenia is considered to be longer than 12 months in duration[4]. There is no clear sequence of therapy for patients who require treatment for chronic or persistent immune thrombocytopenia. The recommendations in guidelines for the preference of one therapy over another are based on limited evidence. The decision of which agent to use should be highly individualized based on age, comorbidities, bleeding risk, barriers to adherence, tolerability profile, cost, and patient preference[7].

Since the first-line treatment for newly diagnosed immune thrombocytopenia is corticosteroids, these agents should not be routinely used for long-term therapy in the setting of chronic immune thrombocytopenia due to adverse effects. There are very few patients who can tolerate prolonged steroid use even at a low dose, and many patients relapse when steroids are stopped[7]. When a patient becomes steroid-dependent, unresponsive to steroids, or cannot tolerate the AEs (Adverse effects), alternative treatments include rituximab, thrombopoietin receptor agonist-RAs, fostamatinib, or a splenectomy. Table 1 outlines current dosages, onset, and adverse effects of numerous treatments for immune thrombocytopenia[6].

Table 1: Treatment strategy for immune thrombocytopenia.

\begin{tabular}{|c|c|c|c|c|c|}
\hline Agent & $\begin{array}{l}\text { Class of } \\
\text { Drug }\end{array}$ & $\begin{array}{c}\text { Route of } \\
\text { administration } \\
\text { and dose }\end{array}$ & $\begin{array}{c}\text { Response } \\
\text { duration }\end{array}$ & Onset & Adverse effects \\
\hline $\begin{array}{c}\text { Romiplostim } \\
\text { (Nplate) }\end{array}$ & $\begin{array}{l}\text { Thrombopoietin } \\
\text { receptor agonist }\end{array}$ & $\begin{array}{c}1-10 \mathrm{mcg} / \mathrm{kg} \mathrm{SC} \\
\text { weekly }\end{array}$ & $\begin{array}{c}\text { Response } \\
\text { achieved and } \\
\text { maintained in } \\
40 \%-60 \% \text {; } \\
\text { sustained } \\
\text { response 30\%- } \\
50 \% \text { after } \\
\text { discontinuation }\end{array}$ & $1-2$ weeks & $\begin{array}{l}\text { Headache, increased risk } \\
\text { of my elofibrosis and } \\
\text { thrombosis, arthralgias }\end{array}$ \\
\hline
\end{tabular}


European Journal of Molecular \& Clinical Medicine

\section{ISSN 2515-8260 Volume 08, Issue 03, 2021}

\begin{tabular}{|c|c|c|c|c|c|}
\hline $\begin{array}{c}\text { Avatrombopag } \\
\text { (Doptelet) }\end{array}$ & $\begin{array}{l}\text { Thrombopoietin } \\
\text { receptor agonist }\end{array}$ & $\begin{array}{c}20-40 \mathrm{mg} \text { PO } \\
\text { weekly or daily }\end{array}$ & $\begin{array}{c}\text { Response } \\
\text { achieved in } \\
65 \% \text { of patients } \\
\text { within } 8 \text { days } \\
\text { after treatment }\end{array}$ & $1-2$ weeks & $\begin{array}{l}\text { Arthralgia, increased risk } \\
\text { of thrombosis, headache }\end{array}$ \\
\hline $\begin{array}{l}\text { Eltrombopag } \\
\text { (Promacta) }\end{array}$ & $\begin{array}{l}\text { Thrombopoietin } \\
\text { receptor agonist }\end{array}$ & $12.5-75 \mathrm{mg}$ PO daily & $\begin{array}{l}\text { Response } \\
\text { achieved and } \\
\text { maintained in } \\
40 \%-60 \% ; \\
\text { sustained } \\
\text { response } 30 \%- \\
50 \% \text { after } \\
\text { discontinuation }\end{array}$ & $1-2$ weeks & $\begin{array}{l}\text { Cataract, diarrhea, } \\
\text { increased risk of } \\
\text { my elofibrosis and } \\
\text { thrombosis }\end{array}$ \\
\hline $\begin{array}{c}\text { Rituximab } \\
\text { (Rituxan) }\end{array}$ & $\begin{array}{l}\text { Anti-CD20 } \\
\text { monoclonal } \\
\text { antibody }\end{array}$ & $\begin{array}{c}375 \mathrm{mg} / \mathrm{m}^{2} \text { IV } \\
\text { weekly for } 4 \text { weeks }\end{array}$ & $\begin{array}{l}\text { Sustained } \\
\text { response in } 60 \% \\
\text { of patients at } 6 \\
\text { months and } \\
30 \% \text { at } 2 \text { years }\end{array}$ & $1-8$ weeks & $\begin{array}{l}\text { Neutropenia, increased } \\
\text { risk of infection, } \\
\text { hypogammaglobulinemia, } \\
\text { infusion-related reaction }\end{array}$ \\
\hline $\begin{array}{c}\text { Fostamatinib } \\
\text { (Tavalisse) }\end{array}$ & $\begin{array}{l}\text { Spleen tyrosine } \\
\text { kinase inhibitor }\end{array}$ & $50-150 \mathrm{mg}$ PO BID & $\begin{array}{l}\text { Response } \\
\text { achieved and } \\
\text { maintained in } \\
18 \%-43 \% \text { of } \\
\text { patients } \\
\text { receiving } \\
\text { continued } \\
\text { therapy }\end{array}$ & $1-2$ weeks & $\begin{array}{l}\text { Transaminitis, nausea, } \\
\text { hypertension, vomiting }\end{array}$ \\
\hline Prednisone & Corticosteroid & $\begin{array}{l}1-2 \mathrm{mg} / \mathrm{kg} \text { PO for 1- } \\
2 \text { weeks, followed } \\
\text { by a gradual taper }\end{array}$ & $\begin{array}{c}30 \%-50 \% \\
\text { sustained } \\
\text { response after } \\
\text { discontinuation }\end{array}$ & $1-2$ weeks & $\begin{array}{l}\text { Acne, mood changes, } \\
\text { weight gain, increased } \\
\text { risk of infection, } \\
\text { insomnia }\end{array}$ \\
\hline Dexamethasone & Corticosteroid & $\begin{array}{c}20-40 \text { mg orally for } \\
4 \text { days every } 2-4 \\
\text { weeks }\end{array}$ & $\begin{array}{c}30 \%-50 \% \\
\text { sustained } \\
\text { response after } \\
\text { discontinuation }\end{array}$ & $1-2$ weeks & $\begin{array}{l}\text { Neuropsychiatric } \\
\text { symptoms, acne, mood } \\
\text { changes, weight gain, } \\
\text { increased risk of } \\
\text { infection, insomnia }\end{array}$ \\
\hline $\begin{array}{l}\text { Human globulin } \\
\text { (Gammagard) }\end{array}$ & $\begin{array}{l}\text { Purified human } \\
\text { IgG }\end{array}$ & $\begin{array}{c}0.4 \mathrm{gm} / \mathrm{kg} / \text { day IV for } \\
\text { upto } 5 \text { days or } 1 \\
\mathrm{gm} / \mathrm{kg} / \text { day for } 1-2 \\
\text { days }\end{array}$ & $\begin{array}{l}\text { Response lasts } \\
1-4 \text { weeks in } \\
\text { upto } 80 \% \text { of } \\
\text { patients }\end{array}$ & 1-4 days & $\begin{array}{l}\text { Renal failure, headache, } \\
\text { aseptic meningitis }\end{array}$ \\
\hline
\end{tabular}


ISSN 2515-8260 Volume 08, Issue 03, 2021

\section{Splenectomy}

A systematic study revealed that in $60 \%$ to $70 \%$ of immune thrombocytopenia patients, splenectomy caused long- lasting remissions[13]. If avoiding long-term medication therapy or achieving a durable response is the patient's priority, a splenectomy might be the preferred treatment for chronic immune thrombocytopenia[8]. A splenectomy should only be considered after the patient has had the diagnosis for 1 year to allow for possible remission before surgery[8]. Short-term risks of splenectomy include postoperative complications, such as venous thromboembolism and sepsis. Patients undergoing splenectomy are at elevated risk of encapsulated bacterial infection and need vaccination. Encapsulated organisms include, but are not limited to, Streptococcus pneumoniae, Haemophilus influenzae, and Neisseria meningitides[7]. A higher incidence of thromboembolic pulmonary hypertension, stroke, and coronary artery disease has also been reported in patients who have undergone splenectomy, but the data are inconsistent among studies[6].

\section{Rituximab}

Rituximab is a monoclonal antibody that targets the CD20 antigen, which is expressed on the surface of pre-B lymphocytes and mature B-lymphocytes [14]. B lymphocyte depletion results in reduced production of platelet-specific antibodies and megakaryocyte glycoproteins [14]. Rituximab may be preferred in a patient who is concerned about the potential financial toxicity of thrombopoietin receptor agonist, or who wants to avoid splenectomy or long-term treatment [8].For the past 10 years, the effectiveness of rituximab in chronic immune thrombocytopenia therapy has been well reported [14]. Rituximab is given for 4 consecutive weeks as a weekly infusion of $375 \mathrm{mg} / \mathrm{m}^{2}$ [15]. A durable response is characterized as a platelet count greater than or equal to $30,000 / \mathrm{mm}^{3}$ to determine the effectiveness of therapy and at least double the baseline count at 6 months[8]. Rituximab has a durable response in about $60 \%$, although only about one-third of patients achieve remission for 3 to 5 years[14, 16].Safety concerns of rituximab include hepatitis $\mathrm{B}$ reactivation,progressive multifocal leukoencephalopathy, mucocutaneous reactions, and infusion-related reactions. Of note, patients with a lymphoproliferative disorder (e.g., chronic lymphocytic leukemia, follicular lymphoma) or who are immunosuppressed are more likely to experience progressive multifocal leukoencephalopathy[14].

\section{Thrombopoietin receptor agonist (Listed in order of FDA approval)}

The thrombopoietin receptor agonistbind and activate the thrombopoietin receptor to increase platelet production[17]. Eltrombopag and avatrombopag are oral nonpeptide drugs, whereas romiplostim is a subcutaneous peptide mimetic agent. Patients who would like to avoid a splenectomy may favor therapy with TPO-RAs[8]. These agents are typically well-tolerated, but they carry a risk of bone marrow fibrosis, which is reversible upon discontinuation. Arterial and venous thrombosis are documented adverse effects, but this is confounded by the disease state because rates of thrombosis are increased in patients with immune thrombocytopenia[7]. 


\section{ISSN 2515-8260 Volume 08, Issue 03, 2021}

\section{Eltrombopag}

Eltrombopag was the first oral agonist of the nonpeptidethrombopoietin receptor approved for chronic immune thrombocytopenia therapy. Initial research found that therapy with eltrombopag for up to 6 months led to an improvement in platelet count in up to 80 percent of patients greater than $50,000 / \mathrm{mm}^{3}$. The extended trial is a phase 3 , open-label, long-term extension study of the efficacy, tolerability, and safety of eltrombopag in patients with immune thrombocytopenia. This trial enrolled 302 patients with a 2.37-year median duration of eltrombopag treatment. The trial found that the long-term use of eltrombopag was successful in sustaining $50,000 / \mathrm{mm}^{3}$ or higher platelet counts and reducing bleeding [18]. Eltrombopag is a daily oral therapy and requires avoidance of divalent cations for administration. For this reason, patients must administer eltrombopag at least 2 hours before or 4 hours after foods high in calcium, supplements such as iron, calcium, magnesium, and zinc, antacids. It is recommended to start with a lower dose or frequency in some patients with Asian ancestry and liver dysfunction. Eltrombopag should be dose-adjusted based on platelet counts and should be held or dose-reduced if patients achieve a platelet count higher than $400,000 / \mathrm{mm}^{3}[18]$. The American Society of Hematology guidelines suggest there is likely no difference in efficacy between eltrombopag and romiplostim; however, the evidence to support this is limited, and there are no head-to-head trials[8, 19]. Hepatic decompensation in patients with hepatotoxicity and chronic hepatitis $\mathrm{C}$ infection are listed as black box warnings; thus, close monitoring of liver function tests is recommended during therapy. Alanine transaminase, aspartate transaminase, and bilirubin should be obtained before treatment initiation[19].

\section{Romiplostim}

Romiplostim is a subcutaneous thrombopoietin receptor agonistinjection approved for adult patients with immune thrombocytopenia who have had an insufficient response to splenectomy, corticosteroids, and immunoglobulins. The initial dose is $1 \mathrm{mcg} / \mathrm{kg}$ per week, and the maximum dose is $10 \mathrm{mcg} / \mathrm{kg}$ per week. It is recommended to use actual body weight when calculating the dose of romiplostim. Doses can be raised weekly in amounts of 1 $\mathrm{mcg} / \mathrm{kg}$ before the patient has a platelet count of $50,000 / \mathrm{mm}^{3}$ or greater[20]. The median onset of action for thrombopoietin receptor agonist is 1 to 2 weeks[6]. If the platelet count does not rise to a degree adequate to prevent bleeding after 4 weeks of therapy at the full dosage $(10 \mathrm{mcg} / \mathrm{kg})$, romiplostim should be stopped. Romiplostim has shown approximately $40 \%$ to $50 \%$ durable response[19]. Outcomes of real-world use in patients are comparable with clinical trial data; however, response patterns are more varied. Results of retrospective and prospective cohort trials have demonstrated that $10 \%$ to $30 \%$ of patients may discontinue therapy following a thrombopoietin receptor agonist and may maintain a response [6]. Romiplostim has the benefit of not suppressing the immune system. However, it is expensive and requires weekly trips to a physician's office. It does not carry any black box warnings, but common adverse effects include headaches, dizziness, bruising, arthralgia, and myalgia[19]. Additionally, romiplostim possibly increases the risk of thrombosis[20]. 


\section{ISSN 2515-8260 Volume 08, Issue 03, 2021}

\section{Avatrombopag}

In June 2019, Avatrombopag received FDA approval for chronic immune thrombocytopenia in adult patients who did not have an appropriate response to prior therapy. The initial dosage should be $20 \mathrm{mg}$ a day and the maximum daily dose should be $40 \mathrm{mg}$ [21]. In phase 2 trials, avatrombopag showed effectiveness and safety. In phase 3, randomized, placebo-controlled trial, participants had chronic immune thrombocytopenia with a platelet count of less than $30,000 / \mathrm{mm}^{3}$ [21]. Forty-nine patients received either avatrombopag or placebo. The primary outcome was the number of weeks of platelet response, identified as greater than $50,000 / \mathrm{mm}^{3}$, without bleeding rescue therapy. Secondary outcomes included the platelet response rate on day 8 and a decline in the use of concomitant drugs. Avatrombopag was superior to placebo for both primary and secondary endpoints and maintained platelet response for a median of 12 weeks (vs 0 weeks for placebo), as well as a greater platelet response of $65 \%$ at day 8 (vs $0 \%$ for placebo). Safety findings were consistent with the previous phase 2 studies, with the most common adverse effect being headaches. There are no black box warnings, but it may cause fatigue, bruising, and arthralgia [21].Avatrombopag should be taken with food because it is a CYP2C9 and CYP3A substrate patients should be routinely tested for drug-drug interactions[17].

When being used for chronic immune thrombocytopenia, it is important to dose-adjust according to the recommended dose titration. While Jurczak and colleagues studied a 20-mg daily dose, the FDA-approved dosing recommends using the lowest available dose to achieve a platelet count higher than $50,000 / \mathrm{mm}^{3}$. This dose may be as low as $20 \mathrm{mg}$ by mouth weekly. There are 6 dosing levels associated with avatrombopag: $20 \mathrm{mg}$ PO weekly, $20 \mathrm{mg}$ PO twice a week or $40 \mathrm{mg}$ PO once weekly, $20 \mathrm{mg}$ three times a week, $20 \mathrm{mg}$ once daily, 40 $\mathrm{mg}$ and $20 \mathrm{mg}$ alternating every other day, and $40 \mathrm{mg}$ once daily. Avatrombopag medication can be stopped if a patient has not reached a platelet count greater than $50,000 \mathrm{~mm}^{3}$ after 4 weeks treatment at the maximum dosage. Also, avatrombopag can also be stopped if a patient exceeds a platelet count greater than $400,000 / \mathrm{mm} 3$ after 2 weeks of the once-weekly $20-\mathrm{mg}$ dosage [21].

\section{Fostamatinib}

In April 2018, Fostamatinib is approved by the FDA as an inhibitor of spleen tyrosine kinase enzyme for patients with chronic immune thrombocytopenia in whom $1^{\text {st }}$ previous therapy has failed[22]. In adults with immune thrombocytopenia, spleen tyrosine kinase signaling is associated with phagocytosis-based, antibody-mediated destruction of platelets. The primary metabolite of fostamatinib, R406, inhibits activation of Fc receptors and B-cell receptors, leading to decreased platelet destruction[17]. Fostamatinib is typically reserved for patients whose other therapies, such as splenectomy, rituximab, or thrombopoietin receptor agonist, have failed. In double-blind placebo-controlled trials, patientstreated with fostamatinib experienced a response (platelets $>50,000 \mathrm{~mm}^{3}$ ) within the first 12 weeks; however, just $18 \%$ had a sustained response at weeks 14 to 24[22]. Further research is needed to determine its place in therapy. The most clinical complication washypertension, transaminitis, dizziness, nausea, anddiarrhea. Fostamatinib is a CYP3A4 substrate that interacts with strong CYP3A4 inhibitors[22]. 


\section{ISSN 2515-8260 Volume 08, Issue 03, 2021}

\section{Other Treatment Options}

When preferred therapies fail, certain immunomodulators, such as mycophenolatemofetil, cyclosporine, azathioprine, or dapsone, may be effective. Evidence is lacking and AEs often preclude their use[7].

\section{Immune Thrombocytopenia in Patients with Cancer}

Cancer-related causes of immune thrombocytopenia include chronic lymphoid leukemia, Hodgkin lymphoma, and large granular T-cell lymphoma[2]. Although standard treatments have shown to be effective and can be used alongside treatment of underlying cancer, prednisone, and intravenous immunoglobulin may not be as effective in patients with immune thrombocytopenia caused by chronic lymphoid leukemia[2]. Rituximab and cyclosporine might be better options in these patients while considering adverse effects and the concurrent treatment of cancer[2]. Chemotherapy agents are known to cause thrombocytopenia; however, this is distinctly different from immune thrombocytopenia, and chemotherapy-induced thrombocytopenia is not recognized as drug-induced immune thrombocytopenia[17]. Drug-induced immune thrombocytopenia is treated by discontinuing the offending agent, whereas chemotherapy-induced thrombocytopenia is treated by reducing chemotherapy doses, adjusting chemotherapy frequency, discontinuing chemotherapy, or providing platelet transfusions[5,17]. The agents used to treat immune thrombocytopenia have not been studied extensively in chemotherapy-induced thrombocytopenia and are not currently recommended[5]. Avatrombopag, eltrombopag, and romiplostim are being studied for safety and efficacy for chemotherapy-induced thrombocytopenia.

\section{Oncology Pharmacists'role in patient care}

Pharmacists have a significant role in the care of patients with chronic immune thrombocytopenia. As oncology pharmacists actively participate in the management of patients with cancer, they can help differentiate among drug-induced immune thrombocytopenia, chemotherapy-induced thrombocytopenia, and immune thrombocytopenia, which is crucial for appropriate treatment [23]. Not only can pharmacists recommend therapy, but they also use collaborative practice with oncologists and other health care professionals to optimize patient care[23]. Pharmacists can monitor laboratory test results, assess the patients, select medications, and regularly follow up with patients to provide the best continuity of care and improve medication adherence and patient satisfaction[23-25]. Upon initiation of new drug therapy, pharmacists should provide verbal and written education, including but not limited to indication, dosing and administration, frequency, goals of therapy, adverse effects, and drug-drug interactions. All patients should be provided with clinical contact information and translator support if needed. Thorough education provided by pharmacists has been proven to increase adherence and patient satisfaction[24]. Oncology pharmacists also have an important role in preparing patients for potential adverse effects. For example, patients who receive corticosteroids should be aware of the risks of short-term and long-term adverse effects[26]. Oncology pharmacists also should be involved in counseling patients on the proper administration of agents used for chronic immune thrombocytopenia (e.g., avoidance of specific vitamins and antacids with eltrombopag and the importance of taking avatrombopag with food)[26]. Additionally, if a 


\section{ISSN 2515-8260 Volume 08, Issue 03, 2021}

splenectomy is a preferred treatment, oncology pharmacists can ensure that the patient is upto-date on recommended vaccinations to mitigate the risk of infection.

Monitoring for drug-drug interactions is essential for patients with chronic immune thrombocytopenia who are treated with drug therapy. Due to their expertise, pharmacists have demonstrated a unique ability to detect drug-related errors when they are included in the management of drug therapy for patients[26]. For example, patients with immune thrombocytopenia starting avatrombopag need to be screened for drug-drug interactions because it is a CYP2C9 and CYP3A4 substrate[21]. Because patients with immune thrombocytopenia may have other comorbidities, pharmacists need to be actively involved in monitoring for drug-drug interactions, disease state interactions, and drug therapy. Patients with immune thrombocytopenia and diabetes will need to be educated on the possibility of corticosteroids having an acute impact on their blood glucose. Additionally, patients with underlying liver dysfunction and immune thrombocytopenia will need to ensure a provider is monitoring for transaminitis if initiating a thrombopoietin receptor agonist[19].Pharmacist involvement in oral chemotherapy programs has been linked to increased interventions surrounding supportive care and laboratory monitoring[24]. As oral agents are utilized extensively in chronic immune thrombocytopenia management, pharmacists should be part of the multidisciplinary team managing these patients.

In educating patients on the importance of conformity, pharmacists may also play an important part. Additionally, improved adherence has been observed among patients who follow up with a pharmacist within the first 3 months of oral chemotherapy[24].Results of numerous studies have demonstrated the impact of a pharmacist on adherence rates among patients on oral anticancer treatment. New research assessing the feasibility of an adaptive oral chemotherapy program showed that patients who were called to evaluate their oral oncolytic twice a month had greater adherence rates than patients who were not proactively approached [27].For patients with chronic immune thrombocytopenia, pharmacists may collaborate with the treatment team to offer continuous adherence assessments.

\section{Conclusion:}

While immune thrombocytopenia was identified two centuries ago, it was only 2-3 years ago that the main portions of immune thrombocytopenia became known. Patients diagnosed with chronic immune thrombocytopenia often face disease-related AEs and experience the impaired health-related quality of life. For more than 60 years the first-line treatment has been corticosteroids while the second-line treatment splenectomy is quite fruitful in treating immune thrombocytopenia. Patients who have complications with surgery are offered rituximab as a second-line procedure to reduce splenectomy, which was found to be very interesting in the study.Oncology pharmacists can educate patients on the importance of attachment to the therapy and also can serve synergistic working relationship among other health care providers which will help patients with their management of chronic immune thrombocytopenia for a better health outcome. 


\section{ISSN 2515-8260 Volume 08, Issue 03, 2021}

\section{Acknowledgment}

The authors are highly thankful to the Library, Dibrugarh University, Dibrugarh for providing the enriched e-resources for the adequate search of relevant journals.

\section{Declaration of Conflicting Interests}

The author(s) declared no potential conflicts of interest with respect to the research, authorship, and/or publication of this article.

\section{Funding}

The author(s) received no financial support for the research, authorship, and/or publication of this article.

\section{References}

1. Bussel, J.B., et al., Long-term fostamatinib treatment of adults with immune thrombocytopenia during the phase 3 clinical trial program. American journal of hematology, 2019. 94(5): p. 546-553.

2. Cines, D.B., et al., The ITP syndrome: pathogenic and clinical diversity. Blood, 2009. 113(26): p. 6511-6521.

3. Swinkels, M., et al., Emerging concepts in immune thrombocytopenia. Frontiers in immunology, 2018. 9: p. 880.

4. Lambert, M.P. and T.B. Gernsheimer, Clinical updates in adult immune thrombocytopenia. Blood, 2017. 129(21): p. 2829-2835.

5. Hassan, M.N. and E.K. Waller, Treating chemotherapy-induced thrombocytopenia: is it time for oncologists to use thrombopoietin agonists? Oncology (Williston Park, NY), 2015. 29(4): p. 295.

6. Cooper, N. and W. Ghanima, Immune thrombocytopenia. New England Journal of Medicine, 2019. 381(10): p. 945-955.

7. Provan, D., et al., Updated international consensus report on the investigation and management of primary immune thrombocytopenia. Blood advances, 2019. 3(22): p. 3780-3817.

8. Neunert, C., et al., American Society of Hematology 2019 guidelines for immune thrombocytopenia. Blood advances, 2019. 3(23): p. 3829-3866.

9. Samson, M., W. Fraser, and D. Lebowitz, Treatments for Primary Immune Thrombocytopenia: A Review. Cureus, 2019. 11(10).

10. Mazzucconi, M.G., et al., Therapy with high-dose dexamethasone (HD-DXM) in previously untreated patients affected by idiopathic thrombocytopenic purpura: a GIMEMA experience. Blood, 2007. 109(4): p. 1401-1407.

11. Cheng, Y., et al., Initial treatment of immune thrombocytopenic purpura with highdose dexamethasone. New England Journal of Medicine, 2003. 349(9): p. 831-836.

12. Mayer, B., et al., New aspects on the efficacy of high-dose intravenous immunoglobulins in patients with autoimmune thrombocytopenia. Vox Sanguinis, 2017. 112(1): p. 64-69.

13. Kojouri, K., et al., Splenectomy for adult patients with idiopathic thrombocytopenic purpura: a systematic review to assess long-term platelet count responses, prediction of response, and surgical complications. Blood, 2004. 104(9): p. 2623-2634.

14. Lucchini, E., F. Zaja, and J. Bussel, Rituximab in the treatment of immune thrombocytopenia: what is the role of this agent in 2019? haematologica, 2019. 104(6): p. 1124-1135. 


\section{ISSN 2515-8260 Volume 08, Issue 03, 2021}

15. Arnold, D.M., et al., Systematic review: efficacy and safety of rituximab for adults with idiopathic thrombocytopenic purpura. Annals of internal medicine, 2007. 146(1): p. 25-33.

16. Bussel, J.B., et al., Rituximab and three dexamethasone cycles provide responses similar to splenectomy in women and those with immune thrombocytopenia of less than two years duration. Haematologica, 2014. 99(7): p. 1264-1271.

17. Clemons Bankston, P. and R.A. Al-Horani, New Small Molecule Drugs for Thrombocytopenia: Chemical, Pharmacological, and Therapeutic Use Considerations. International journal of molecular sciences, 2019. 20(12): p. 3013.

18. Wong, R.S., et al., Safety and efficacy of long-term treatment of chronic/persistent ITP with eltrombopag: final results of the EXTEND study. Blood, 2017. 130(23): p. 2527-2536.

19. Yang, R., et al., Therapeutic options for adult patients with previously treated immune thrombocytopenia-a systematic review and network meta-analysis. Hematology, 2019. 24(1): p. 290-299.

20. McGrath, L.J., et al., Treatment Patterns Among Adults with Primary Immune Thrombocytopenia Diagnosed in Hematology Clinics in the United States. Clinical Epidemiology, 2020. 12: p. 435.

21. Jurczak, W., et al., Phase 3 randomised study of avatrombopag, a novel thrombopoietin receptor agonist for the treatment of chronic immune thrombocytopenia. British journal of haematology, 2018. 183(3): p. 479-490.

22. Bussel, J., et al., Fostamatinib for the treatment of adult persistent and chronic immune thrombocytopenia: results of two phase 3, randomized, placebo-controlled trials. American journal of hematology, 2018. 93(7): p. 921-930.

23. Holle, L.M., et al., Pharmacists' roles in oncology pharmacy services: Results of a global survey. Journal of Oncology Pharmacy Practice, 2017. 23(3): p. 185-194.

24. Muluneh, B., et al., Improved adherence rates and clinical outcomes of an integrated, closed-loop, pharmacist-led oral chemotherapy management program. Journal of oncology practice, 2018. 14(6): p. e324-e334.

25. Mackler, E., et al., 2018 Hematology/Oncology Pharmacist Association Best Practices for the Management of Oral Oncolytic Therapy: Pharmacy Practice Standard. Journal of oncology practice, 2019. 15(4): p. e346-e355.

26. Dillmon, M.S., et al., Patient-centered standards for medically integrated dispensing: ASCO/NCODA standards. Journal of Clinical Oncology, 2020. 38(6): p. 633-644.

27. Morgan, K.P., et al., Impact of an integrated oral chemotherapy program on patient adherence. Journal of Oncology Pharmacy Practice, 2018. 24(5): p. 332-336. 